\title{
COMPARISON OF ZIEHL-NEELSEN, KINYOUN'S AND FLUORESCENT STAINING FOR DETECTION OF MYCOBACTERIUM TUBERCULOSIS IN SPUTUM SAMPLES BEFORE AND AFTER PETROFF'S CONCENTRATION TECHNIQUE
}

\author{
NEELU SREE P*, TERIN J, HIMADRI DUTTA, KALYANI M \\ Department of Microbiology, Saveetha Medical College, Thandalam, Chennai, Tamil Nadu, India. Email: drneelu2007@gmail.com \\ Received: 22 November 2017, Revised and Accepted: 19 December 2017
}

ABSTRACT

Objectives: The objectives of the study were to find out the presence of Mycobacterium tuberculosis in sputum samples using Ziehl-Neelsen (ZN), Kinyoun's, and (auramine) fluorescent staining and to compare the three staining techniques with and without Petroff's concentration and to find out the most preferable staining of M. tuberculosis.

Methods: Sputum sample was collected and concentrated by $4 \% \mathrm{NaOH}$ (Petroff's concentration). Microscopic examination of the sample was done before concentration and after concentration by ZN staining, Kinyoun's staining, and fluorescent staining (Auramine). Grading of acid-fast bacilli (AFB) by three staining was done before and after concentration according to RNTCP guidelines.

Results: Total of 452 sputum samples were collected and subjected to microscopy examination by ZN, Kinyoun's, and fluorescent staining methods to compare the presence or absence of AFB with or without concentration. Among the 452 sputum samples, total of 67 (15.6\%) sputum samples were positive for the presence of AFB. Majority $40.3 \%(n=21)$ of TB positive patients were observed in the age group $51-60$ years. The results of Auramine-O staining showed positive diagnoses in $15.9 \%$ of the samples; sensitivity was $100 \%$ and specificity $95.6 \%$.

Conclusion: The use of fluorescent staining significantly increases the diagnostic value of the smear, particularly where there are low-density bacilli which may escape detection on ZN stained smears.

Keywords: Mycobacterium tuberculosis, Ziehl-Neelsen, Kinyoun's staining, Fluorescent staining, Petroff's concentration technique.

(C) 2018 The Authors. Published by Innovare Academic Sciences Pvt Ltd. This is an open access article under the CC BY license (http://creativecommons. org/licenses/by/4. 0/) DOI: http://dx.doi.org/10.22159/ajpcr.2018.v11i4.23662

\section{INTRODUCTION}

Tuberculosis (TB) remains a major global health problem. Mycobacterium tuberculosis infects almost the third part of the world population killing around 2 million people worldwide each year. About $80 \%$ of the global TB burden is in low-income countries, where pulmonary disease and transmission are serious public health problems. TB ranks as the second leading cause of death from an infectious disease worldwide, after the Human Immunodeficiency Virus (HIV). The latest reports shows that one-fourth of the global incident TB cases occurred in India annually making India, the world's highest TB burden country. In 2014, TB killed 1.5 million people (1.1 million HIV-negative and 0.4 million HIV-positive). The toll comprised 890,000 men, 480,000 women, and 140,000 children. In 2014, 6 million new cases of TB were reported to the WHO, fewer than two-thirds (63\%) of the 9.6 million people estimated to have fallen sick with the disease. This means that worldwide, $37 \%$ of new cases went undiagnosed or were not reported. The quality of care for people in the latter category is unknown.

Although M. tuberculosis is the most important mycobacterial species from a public health perspective [1], other species of non TB (NTB) mycobacteria are also being encountered with increasing frequency, and new species are being identified. Pathogenic NTBs are usually less virulent than M. tuberculosis, and they are isolated in TB suspected cases. Because they are of low virulence mostly, they are considered as either colonizers or coincidental contaminants from the environment. On the contrary, species usually considered benign may produce disease, especially in immune-compromised individuals [2].

The most common method for diagnosing TB worldwide is sputum smear microscopy (developed more than 100 years ago), in which bacteria are observed in sputum samples examined under a microscope.
In countries with more developed laboratory capacity, cases of TB may also be diagnosed through culture methods (the current gold standard) or, increasingly, using rapid molecular tests.

It is agreed that the only positive evidence of TB disease is the demonstration of the tubercle bacillus. It is also recognized that bacilli, to be demonstrated by the usual direct smear method, must be present in abundance; estimated that 2000 to the cubic millimeter are necessary. When we consider the minute amount of material that we actually see during an immersion lens study, this is not surprising, and it will be agreed that our chances of finding the bacilli must be mathematically small unless they are present in considerable numbers.

The isolation of mycobacteria from specimens contaminated with normal flora like sputum poses a problem, and these specimens have to be treated to kill various non-acid fast organisms by decontamination techniques. A great variety of decontamination methods are in existence, and different laboratories use different decontamination techniques, but no single method is entirely satisfactory. At present, for diagnosis of TB, smear microscopy is still the most used among all methods employed worldwide due to its simplicity, low cost, speed, and minimal requirement of equipment and technical skills. Although it lacks sensitivity since a load of about $5000-10,000$ bacilli/ml of the specimen is required to give a positive result after Ziehl-Neelsen (ZN) staining. In developing countries, culture on Lowenstein-Jensen solid medium is the gold standard for microbiological diagnosis of TB and requires about 10 bacilli/ $\mathrm{ml}$ of specimen for recovery of mycobacteria. The slow growth rate of the pathogen leads to a delay of 4-6 weeks in obtaining a definitive diagnosis $[3,4]$. Since sputum microscopy is the cornerstone of TB diagnosis, a more sensitive smear microscopy and decontamination method would both be useful in clinical laboratories 
so as to achieve increased, accurate and rapid TB diagnosis. In this study, Petroff's method is compared with modified Petroff's method

At present, two types of acid-fast stains are used in clinical mycobacteriology laboratories. One type is carbol fuchsin (ZN or Kinyoun methods), and the other is fluorochrome (either auramine or auramine-rhodamine). The present ZN method has evolved from Koch's original alkaline methylene blue-based method following significant modifications. Kinyoun's cold staining is a modification of the classical ZN method that excludes the heating step during staining, and therefore, uses a higher concentration of carbol fuchsin.

\section{METHODS}

This study was carried out in a tertiary care hospital on clinically suspected $M$. tuberculosis inpatients and outpatients. Sputum sample was collected and concentrated by $4 \% \mathrm{NaOH}$ (Petroff's concentration). Microscopic examination of the sample was done before concentration and after concentration by ZN staining, Kinyoun's staining and fluorescent staining (Auramine). Grading of acid-fast bacilli (AFB) by three staining was done before and after concentration according to RNTCP guidelines.

In TB bacteriology an often-overlooked problem is that of obtaining adequate specimens. The advantages of decontamination techniques, sensitive culture media and simple identification schemes will not be complete unless specimens are collected with care and promptly transported to the laboratory.

A good sputum specimen consists of recently discharged material from the bronchial tree, with minimum amounts of oral or nasal material. Satisfactory quality implies the presence of mucoid or mucopurulent material and is of greater significance than volume. Ideally, a sputum specimen should have a volume of approximately $5 \mathrm{ml}$, although smaller quantities are acceptable if the quality is satisfactory. Two types of sputum samples approximately $5 \mathrm{ml}$; spot and early morning were collected after suitable instructions to the patient. The specimen was transported to the laboratory as soon as possible after collection.

About $5 \mathrm{ml}$ of sputum sample was taken and divided into two equal amounts. From one portion of the sample, ZN staining, Kinyoun's staining, and Auramine staining were performed. The other portion is mixed with $2 \mathrm{ml}$ of $4 \% \mathrm{NaOH}$ and centrifuged at $3000 \times$ g for $15 \mathrm{~min}$. After the decontamination, process pellet is taken, and ZN staining, Kinyoun staining, and Auramine staining were performed. With these six slides (2 ZN, 2 Kinyoun, and 2 Auramine) presence or absence of AFB was examined. Procedures of various staining techniques for AFB and grading of AFB were as per guidelines (Tables 1-3).

\section{RESULT}

The present study was done for a period of 3 months, from April 2016 to June 2016 and a total of 452 sputum samples were collected from suspected cases of pulmonary TB of patients attending inpatient and outpatient Department of General Medicine and thoracic medicine of a tertiary care hospital (Fig. 1).

A total number of 452 sputum samples were collected and subjected to microscopy examination by ZN, Kinyoun's and fluorescent staining methods to compare the presence or absence of AFB with or without concentration. Among the 452 sputum samples, total of 67 (15.6\%) sputum samples were positive for the presence of AFB (Fig. 2).

Gender distribution and age distribution are shown in Figs. 3 and 4. In this present study majority, $40.3 \%(n=21)$ of TB positive patients were observed in the age group 51-60 years.

Tables 4 and 5 summarize the rate of positivity of AFB picked up by various staining techniques before and after Petroff's concentration among the total positive samples ( $n=67)$. Comparison before and after Petroff's concentration (ZN, Kinyoun's and fluorescent staining) shown in Fig. 5.
Table 1: Grading of AFB by ZN staining

\begin{tabular}{|c|c|c|}
\hline Examination Result & Grading Number & $\begin{array}{l}\text { Number of } \\
\text { fields to be } \\
\text { examined }\end{array}$ \\
\hline $\begin{array}{l}\text { More than } 10 \text { AFB per } \\
\text { oil immersion field }\end{array}$ & Positive 3+ & 20 \\
\hline $\begin{array}{l}\text { 1-10 AFB per oil } \\
\text { immersion field }\end{array}$ & Positive & 50 \\
\hline $\begin{array}{l}\text { 10-99 AFB per oil } \\
\text { immersion field }\end{array}$ & Positive & 100 \\
\hline 1-9 AFB per oil & Positive & 100 \\
\hline immersion field & $\begin{array}{l}\text { Scanty } \\
\text { (Record exact } \\
\text { number seen) }\end{array}$ & \\
\hline $\begin{array}{l}\text { AFB per } 100 \text { oil } \\
\text { immersion fields }\end{array}$ & Negative & 100 \\
\hline
\end{tabular}

AFB: Acid-fast bacilli, ZN: Ziehl-Neelsen

Table 2: Grading of AFB by Kinyoun's staining

\begin{tabular}{|c|c|c|}
\hline Examination Result & Grading Number & $\begin{array}{l}\text { Number of } \\
\text { fields to be } \\
\text { examined }\end{array}$ \\
\hline $\begin{array}{l}\text { More than } 10 \mathrm{AFB} \\
\text { per oil immersion } \\
\text { field }\end{array}$ & Positive $3+$ & 20 \\
\hline $\begin{array}{l}\text { 1-10 AFB per oil } \\
\text { immersion field }\end{array}$ & Positive & 50 \\
\hline $\begin{array}{l}\text { 10-99 AFB per oil } \\
\text { immersion field }\end{array}$ & Positive & 100 \\
\hline 1-9 AFB per oil & Positive & 100 \\
\hline immersion field & $\begin{array}{l}\text { Scanty } \\
\text { (Record exact } \\
\text { number seen) }\end{array}$ & \\
\hline $\begin{array}{l}\text { AFB per } 100 \text { oil } \\
\text { immersion fields }\end{array}$ & Negative & 100 \\
\hline
\end{tabular}

AFB: Acid-fast bacilli

The results of Auramine-O staining showed positive diagnoses in $15.9 \%$ of the samples; sensitivity was $100 \%$, specificity $95.6 \%$, and the positive and negative predictive values $84.4 \%$ and $100 \%$, respectively. Kinyoun's staining produced a positive diagnosis rate of $15.6 \%$, sensitivity of $96.4 \%$, specificity of $99.5 \%$, and positive and negative predictive values of $96.4 \%$ and $99.5 \%$. SPSS Statistics is a Software package used for statistical analysis.

\section{DISCUSSION}

In this present study, during a period of 3 months (April 2016 to June 2016), a total of 452 sputum samples were collected from both inpatients and outpatients attending General Medicine and Thoracic medicine department of a tertiary care hospital.

In this present study, age group between 51 and 60 years recorded the highest prevalence rate of $36 \%$ and the age group between 11-20 and 81-90 recorded the lowest prevalence rate of $13.1 \%$ similarly the distribution of smear positive cases with respect to gender in this study was found out to be $52.3 \%$ for males and $47.7 \%$ for females. The proportion of male patients was higher than female patients. With increasing age, the rates are higher in males. This difference is most marked in the age group 51-60 years. The prevalence rate of male above 50 years was $90 \%$. Similar to study reported by Makeshkumar et al. [5], which revealed that $59.8 \%$ were male and $40.2 \%$ were female. The prevalence rate of male above 50 years was $95 \%$.

Similar results were also seen in studies done by Mukherjee et al. [6], who reported $63.3 \%$ male and $35.7 \%$ female and the increased 
Table 3: Grading of AFB by fluorescent staining

\begin{tabular}{|c|c|}
\hline \multirow{2}{*}{$\begin{array}{l}\text { IUATLD/WHO } \\
\text { scale }(1000 \times \text { field=HPF }) \\
\text { result }\end{array}$} & Microscopy system used \\
\hline & $\begin{array}{l}\text { Fluorescence }(400 \times \text { magnification: } \\
1 \text { length }=40 \text { fields }=200 \mathrm{hpf})\end{array}$ \\
\hline Negative & Zero AFB/3 length \\
\hline Scanty & 1-19 AFB/4 length \\
\hline $1+$ & 20-199 AFB/4 length \\
\hline $2+$ & 5-50 AFB/1 field on average \\
\hline $3+$ & $>50 \mathrm{AFB} / 1$ field on average \\
\hline
\end{tabular}

Table 4: Rate of positivity of AFB picked up by various staining techniques before Petroff's concentration

\begin{tabular}{llll}
\hline $\begin{array}{l}\text { Staining } \\
\text { methods }\end{array}$ & Positive & Negative & Total \\
\hline ZN method & 60 & 392 & 452 \\
Kinyoun's method & 58 & 394 & 452 \\
Fluorescent & 65 & 387 & 452 \\
\hline
\end{tabular}

AFB: Acid-fast bacilli

Table 5: Rate of positivity of AFB picked up by various staining techniques after Petroff's concentration

\begin{tabular}{llll}
\hline $\begin{array}{l}\text { Staining } \\
\text { methods }\end{array}$ & Positive & Negative & Total \\
\hline ZN method & 65 & 387 & 452 \\
Kinyoun's method & 60 & 392 & 452 \\
Fluorescent & 67 & 385 & 452 \\
\hline
\end{tabular}

AFB: Acid-fast bacilli

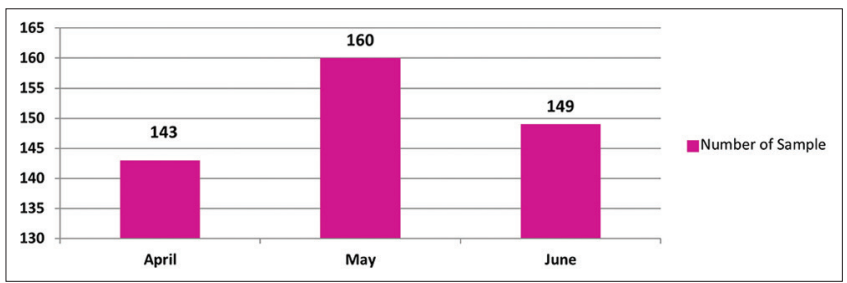

Fig. 1: Summary of samples over the study period

incidence of TB in male aged above 50 years. Rao et al. [7], in his study report $62 \%$ male and $38 \%$ female.

Chandha et al. [8], the study concluded that the prevalence was about 6 times higher among male compared to female and generally increased with age. TB Annual report reveals that in older age groups the incidence of TB is much higher among male than among female.

AFB smear microscopy using conventional light microscope still remains the mainstay for diagnosis and monitoring treatment of TB as it is simple, inexpensive, widely applicable and highly specific for TB in endemic countries.

In this study, the total number of sputum smear-positive samples detected by microscopic examination by ZN staining method was found out to be $76(8.4 \%)$. This result by microscopic examination by ZN staining method could be correlated to the study by Makeshkumar et al. [5], which reports that $12.13 \%$ were smear positive for AFB in Kanchipuram district, South India.

The sensitivity of ZN staining method was increased by $28 \%$ after concentration method. This can be correlated to Hooja et al. [9], study which describes the sensitivity of direct staining was $55.55 \%$ by ZN

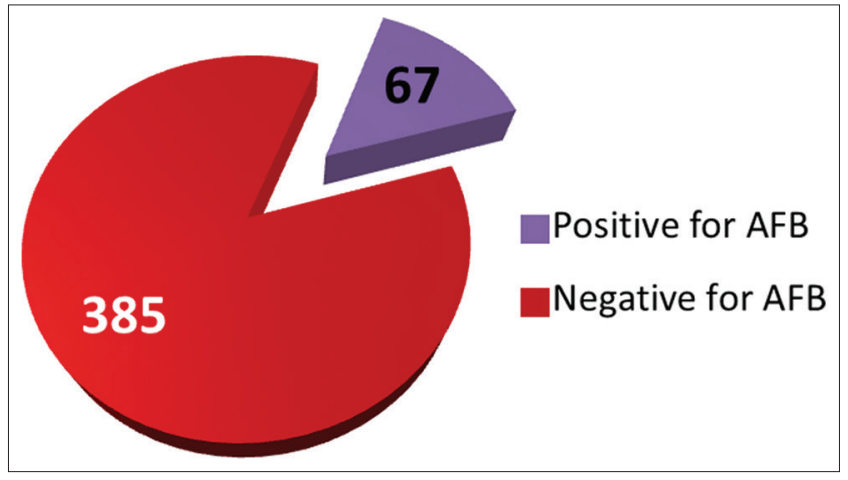

Fig. 2: Distribution of sputum samples

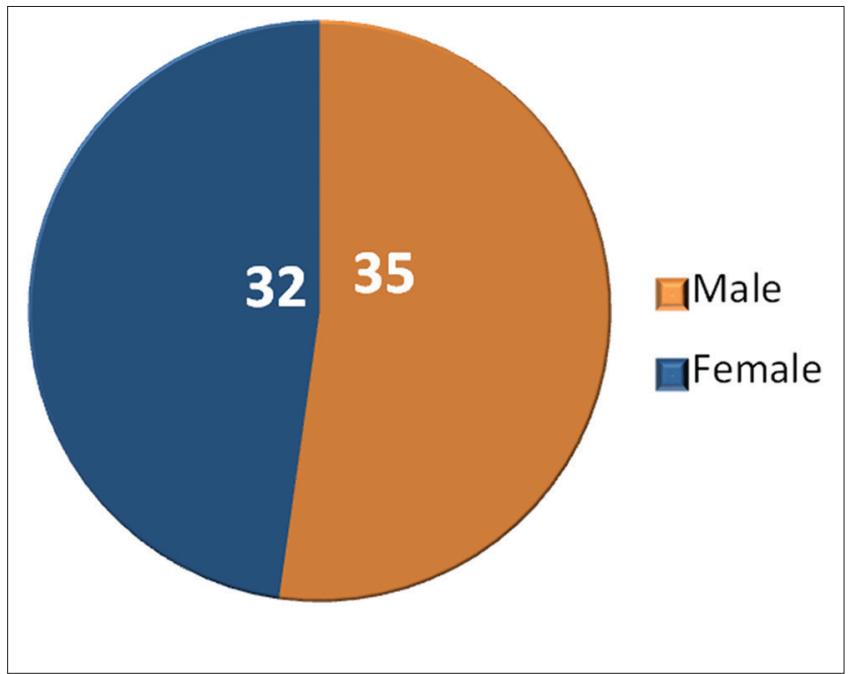

Fig. 3: Gender distribution of positive sputum samples

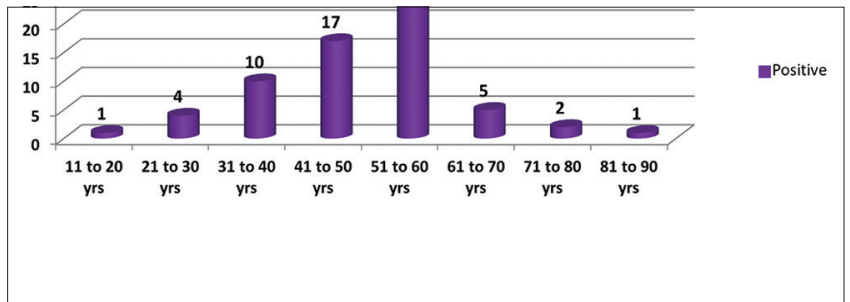

Fig. 4: Age distribution of tuberculosis confirmed patients

staining. On concentration, the sensitivity was reported to increase by $6.67 \%$ for ZN.

The results from the study indicated that almost $88.1 \%$ of TB cases were detected with the first sputum specimen. With the second sputum specimen, the average incremental yield was $11.9 \%$. Similar results were seen in studies by Ulukanligil et al. [10], which reports that $85 \%$ of the cases were detected with the first sputum sample and $11.9 \%$ with the second sample.

It was found that the specificities of fluorescent staining and ZN staining were $99 \%$ and $100 \%$, and the sensitivities with one sample were $83 \%$ and $61 \%$, respectively. When the number of specimens was increased, the sensitivity of both types of staining increased. When we utilized more than two specimens, the sensitivities were found to be similar [11-15]. Therefore, it is possible to say that if we have less than three samples, the reliability of fluorescent staining is much greater than that of ZN staining. Unless more than one sample was submitted, which were not easy existing socioeconomic and cultural conditions, 


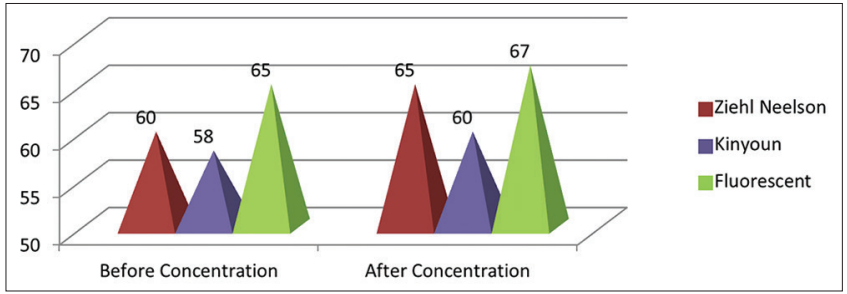

Fig. 5: Comparison before and after Petroff's concentration (ZN, Kinyoun's, and fluorescent staining)

fluorescent staining proved to be more reliable than the ZN staining method. Moreover, another advantage of fluorescent staining was that it enabled the detection of positive smears, which were overlooked with ZN stained smears containing low-density bacilli. The use of fluorescent staining significantly increases the diagnostic value of the smear, particularly where there are low-density bacilli which may escape detection on ZN stained smears.

\section{CONCLUSION}

In this present study, done for a period of 3 months, a total of 452 sputum samples were collected and analyzed. Among the total sputum samples $\mathrm{n}=67$ were found to be AFB positive with the majority in the age group 51-60 years, with higher distribution among males than females. With or without Petroff's concentration the reliability of fluorescent staining is much greater than that of ZN staining. The use of fluorescent staining significantly increases the diagnostic value of the smear, particularly where there are low-density bacilli which may escape detection on ZN stained smears.

\section{REFERENCES}

1. Siddiqui S, Baig MM, Jaffer S, Ansari SF. Study on prevalence of adverse drug reactions in patients suffering from tuberculosis in a tertiary care hospital. Int J Pharm Pharm Sci 2016;8: 273-6.

2. Hudu SA, Shinkafi SH, Umaran S. Overview of recombinant vaccine technology, adjuvants and vaccine delivery methods. Int J Pharm Pharm Sci 2016;8:19-24.

3. WHO. Global Tuberculosis Control: Surveillance, Planning, Financing. Geneva: WHO Report; 2007. p. 1-37.

4. WHO. Global Tuberculosis Control: Planning, Surveillance, Financing. Geneva: WHO Report; 2015. p. 16-45.

5. Makeshkumar V, Madhavan R, Narayanan S. Prevalence of drug resistance in Mycobacterium tuberculosis in a teaching hospital of Kanchipuram district, Tamil Nadu, South India. Am J Microbiol Res 2014;2:35-40

6. Mukherjee A, Vasanthakumari R, Jaganath K, Rajasekaran S. A cold staining method for acid-fast bacilli. Bull WHO 1986;64:741-3.

7. Rao S, Rao KP, Nagpaul DR. Bacteriological diagnosis of pulmonary tuberculosis-sputum microscopy. Bull IUAT 1970;44:67-7.

8. Chandha VK, Madan M, Ranjitham M, Lakshman C. Cold staining method for acid fast bacilli. Ind J Pathol Microbiol 1999;42:505-7.

9. Hooja S, Gokhle S, Qadir S, Nagra JJ, Chakraborty AK. Efficiency of cold staining method of AFB in sputum-A comparison with ziehl neelsan method under field conditions. Ind J Tub 1990;37:135-7.

10. Ulukanligil M, Aslan G, Tasçi S. A comparative study on the different staining methods and number of specimens for the detection of acid fast bacilli. Mem Inst Oswaldo Cruz 2000;95:855-8

11. Park JE, Park K. Epidemiology of communicable disease. In: Text book of Preventive and Social Medicine. $13^{\text {th }}$ ed.,. Jabalpur: Banaresidas Bhenot; 2007. p. 149-66.

12. Kinyoun JJ. A note on Uhlenhuth's method for sputum examination for tubercle bacilli. Am J Public Health 1915;5:867-9.

13. Hok TT. Simple and rapid cold staining method for acid-fast bacteria. Am Rev Respir Dis 1962;85:753-4

14. Ananthanarayan R, Paniker CK. Mycobacterium I: Tuberculosis. In: Ananthanarayan and Paniker's Textbook of Microbiology. $8^{\text {th }}$ ed. Hyderabad: Universities Press (India) Pvt Ltd.; 2009. p. 353.

15. Module for Laboratory Technicians. Revised National Tuberculosis TB Control Programme. New Delhi: Central TB Division, Directorate General of Health Services, I G Printers Ltd.; 2005. p. 26. 